\title{
VENOUS HUMS IN HEPATIC CIRRHOSIS
}

BY

\author{
H. J. G. BLOOM
}

From the Middlesex Hospital, London

Received January 27, 1949

Pégot in 1833, addressing the members of the Anatomical Society of Paris, described a murmur heard over subcutaneous abdominal varices in an alcoholic soldier. From this time, cases of cirrhosis with so-called abdominal " venous hums " have been reported at intervals. Judging from the total number mentioned, this physical sign is infrequent but failure of recognition may account in part for this. There are 60 recorded instances with necropsies in 25, Continental and American authors having been the chief contributors. There have been few references to the sign published in this country. The object of this paper is to report two further cases with post-mortem findings in one; to describe the features of the hum and discuss its origin, and to consider other murmurs with which it may be confused. Auscultation of the abdomen is seldom performed, but attention will be drawn here to this simple clinical procedure, which may yield useful information, particularly in suspected chronic liver disease and splenomegaly of doubtful ætiology.

Case 1. An Italian woman, aged 62, was admitted in emergency to the Middlesex Hospital, on November 2, 1947. She had apparently been healthy until that day, when dark blood had suddenly welled from her mouth. She became pale and collapsed.

The patient had come to England in 1903. There was no past history of illness until 1940, when she had a distended abdomen and what was described as " anæmia and dropsy of the belly." She was treated at home with injections and after three months the distension subsided, without recurrence. She had been pale and thin for many-years. There were no symptoms referable to the cardiovascular, respiratory, and alimentary systems. A glass of beer was taken every day, and occasionally spirits. A few of the details in the following account were obtained at a later examination when the patient's general condition had improved.

On examination the patient was pale and wasted. The skin was rough, sallow, and lax. Numerous prominent small vessels were present on the nose. The pulse was 100 a minute and regular, and the blood pressure 105/70. The cervical veins were not congested. Over the angle of Louis a zone of pulsation, $16 \mathrm{~mm}$. in diameter, was visible, but not palpable. A dilated tortuous vein, $3.7 \mathrm{~cm}$. in length, was lying longitudinally just below the tip of the xiphoid; the blood-flow was upwards. Pressure in the epigastrium resulted in obliteration of the pulsation at the sternomanubrial junction. The superficial veins of the abdomen and of the lower limbs were prominent and tortuous, the flow of blood being in the normal direction.

The apex beat was in the fifth left intercostal space, $12.5 \mathrm{~cm}$. from the mid-line. A soft systolic murmur was audible at the apex. As the stethoscope was moved medially away from the apex, a strange, distant, blowing sound was heard. It was high-pitched, continuous, and of constant intensity, resembling the sound produced by a sea-shell held against the ear. The intensity of the bruit increased, becoming a continuous, loud roar as the mid-line was approached. It was maximal in the epigastrium, especially over the varicosity. The murmur was audible, with diminishing intensity, over the lower part of the right side of the chest and over the upper abdomen as far laterally as the mid-axillary line. (Fig. 1). The character and intensity of the murmur were not influenced 
by the phases of the respiratory and cardiac cycles, nor by change of posture. Light digital palpation of the varicose vein in the epigastrium revealed a slight thrill. Firm pressure over the xiphoid process caused the hum to cease abruptly; on releasing the compression the hum reappeared.

The spleen was grossly enlarged, the tip extending beyond the level of the umbilicus. The liver edge was just palpable; it was hard and regular. Shifting dullness was not demonstrated. External hæmorrhoids were present.

A diagnosis of portal hypertension, probably secondary to hepatic cirrhosis, was made. The history of dark blood welling from the mouth suggested the presence of bleeding osophageal varices. Examination of the blood showed: hæmoglobin, 50 per cent (Haldane); red cells, $2.8 \mathrm{~m}$. per cu. mm.; leucocyte count, 2500 per cu. mm. The Van den Bergh reaction and liver function precipitation tests were normal. The Wassermann reaction was negative in the blood.

The patient had repeated hæmatemeses with effortless vomiting, and, in spite of transfusions, died on December 1, 1947. No change was observed in the character, intensity, and distribution of the continuous murmur during the period of observation.

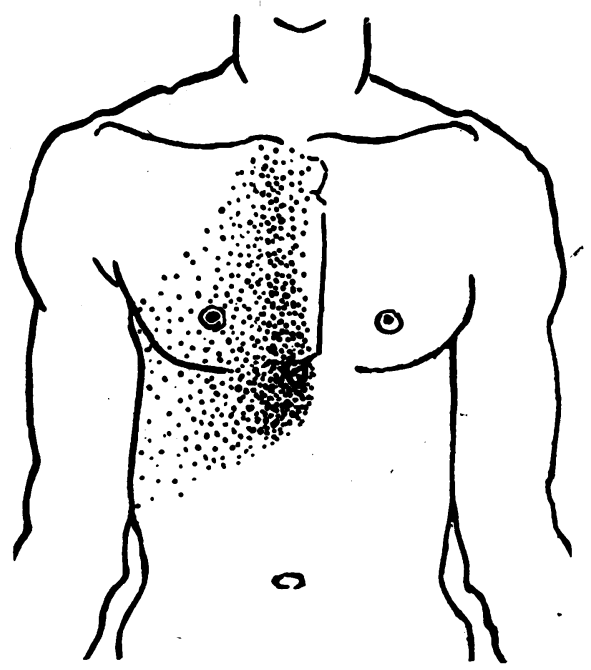

Fig. 1. Shows the distribution and intensity of the venous hum in Case 1.

Abstract from Post-mortem Record (Bland-Sutton Institute, No. 228/47). Nothing abnormal was found in the heart, great vessels, or lungs. Blood clots were présent in the lumen of the œsophagus, and dilated tortuous veins in the submucosa, extending from the cardia to the level of the aortic arch. A circular perforation, $5 \mathrm{~mm}$. in diameter, was found in a vessel $8 \mathrm{~cm}$. from the cardia.

There was no free fluid in the abdomen. The stomach and intestines were normal. The liver was finely nodular and weighed $1.2 \mathrm{~kg}$; ; the microscopic appearances were those of an early coarse cirrhosis. The spleen was grossly enlarged, weighing nearly $1 \mathrm{~kg}$; ; microscopy revealed dilated sinuses, diffuse fibrosis, and siderotic nodules.

The inferior vena cava was normal. The portal and splenic veins were much dilated and their walls calcified. A dilated vessel, $1.7 \mathrm{~cm}$. in diameter, was found arising from the left branch of the portal vein. It passed into the falciform ligament and after a distance of $8.7 \mathrm{~cm}$. turned upwards from the free margin to run tortuously through the linea alba into the superficial tissues of the abdominal wall. The remaining part of the free margin contained the ligamentum teres. The vein appeared just below the tip of the xiphoid and, passing anteriorly'to the process, widened to form a thin-walled sinus $18 \mathrm{~mm}$. in diameter. The sinus united with the dilated left and right internal mammary veins which ran a normal course beneath the chest wall (Fig. 2). 
Final Diagnosis. Coarse cirrhosis with a collateral circulation in the falciform ligament and abdominal wall, producing a venous hum and thrill. Esophageal varices with perforation.

Comments. The long symptomless history, dating from the sudden onset and rapid disappearance of ascites seven years ago, is unusual in coarse cirrhosis. Thrombosis of the portal vein may have occurred at that time with subsequent recanalization. Banti's syndrome may be considered as a possible diagnosis. This view is supported by the long history, the leucopenia, and the gross splenic enlargement, but in the absence of previous medical records this diagnosis remains only a possibility.

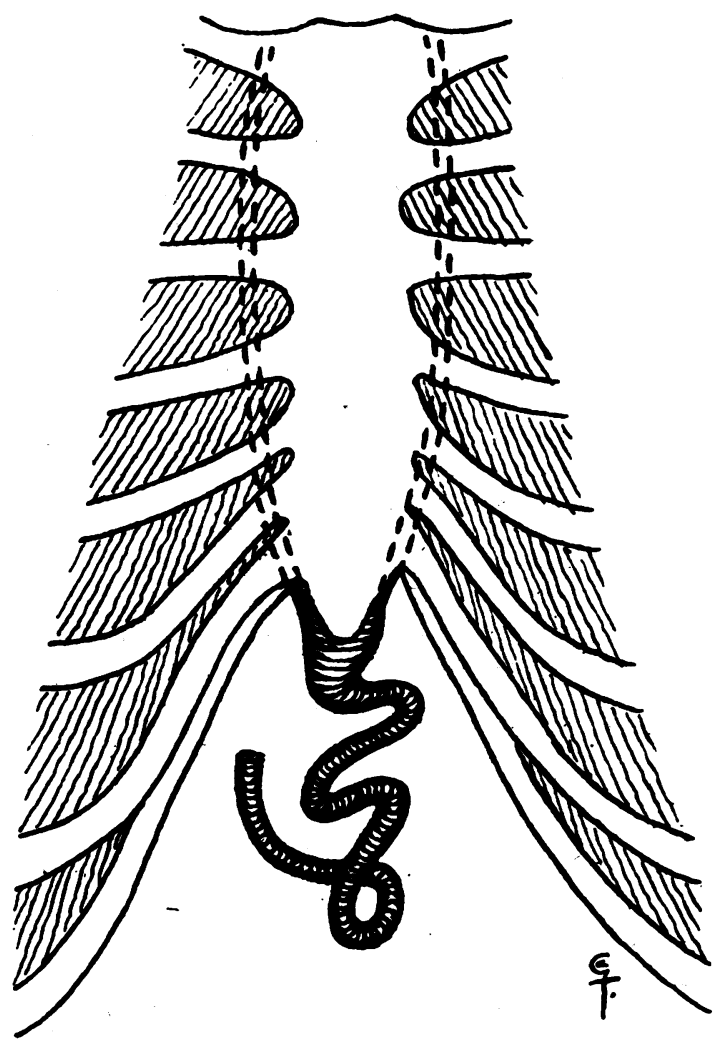

Fig. 2.-Shows the course of the venous sinus arising from the left branch of the portal vein and terminating in the dilated internal mammary veins, in Case 1.

Case 2. An Italian man, aged 67, was admitted to the Middlesex Hospital on March 12, 1948. On the day before admission, while he was walking in the street, his mouth had suddenly filled with blood. The total hæmorrhage amounted to about a quarter of a litre. No other symptoms accompanied the bleeding, apart from some weakness.

There was no past history of illness except " jaundice" at the age of 17 . The patient came to London in 1906 and was well until March, 1942, when he had a sudden, severe melæna, and was admitted to St. Mary's Hospital. At that time the spleen was found to be palpable, and no organic lesion was demonstrated by radiological examination of the alimentary tract. A diagnosis of Banti's disease was made. He remained well until February, 1944, when he was admitted to the Middlesex Hospital for a sudden and severe hæmatemesis. The liver edge was just palpable and the spleen enlarged three fingers-breadth below the costal margin. Blood examination showed: hæmoglobin, 67 per cent (Haldane); red cells, $3.3 \mathrm{~m}$. per cu. $\mathrm{mm}$.; leucocyte count, 
4000 per cu. $\mathrm{mm}$. Platelet count, 160,000 per cu. $\mathrm{mm}$. A barium swallow revealed gross œsophageal varices.

Following his discharge from hospital in April, 1944, the patient was seen in the out-patient department at intervals. His general condition remained very good, the hæmoglobin high $(90$ 108 per cent) and the platelet count low (70,000-250,000 per cu. mm.). He now complained of increasing fatigue on moderate exertion. The appetite was good and the weight steady. There was occasional epigastric discomfort. Beer and spirits were taken rarely.

On examination the skin was sallow and lax, with telangiectases over the nose. The pulse was normal, and the blood pressure 125/80. No varicosities were visible on the trunk or lower limbs. Examination of the heart and lungs revealed no abnormality. The spleen and the liver were enlarged, each two fingers' breadth below the corresponding costal margin. No ascites was detected. Light palpation over the xiphoid revealed a continuous thrill. A loud, continuous, roaring murmur was audible, localized to the xiphoid region, and loudest at the base of the process (Fig. 3). The intensity was increased in the erect posture compared with the recumbent, reaching

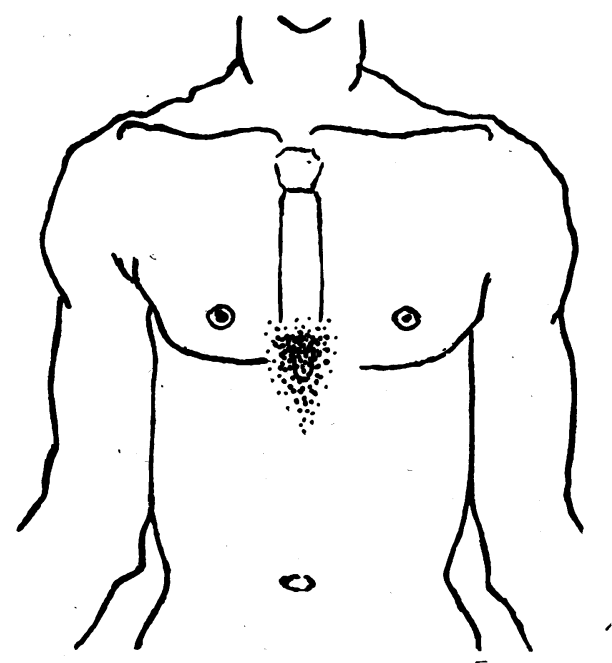

Fig. 3. - Shows the distribution of the venous hum in Case 2.

a crescendo at the height of inspiration. There was no accentuation during cardiac systole. The thrill and bruit ceased abruptly upon the application of firm, localized pressure just below the tip of the xiphoid. Subcutaneous varices were neither visible nor palpable in this region.

Blood examination showed: hæmoglobin, 91 per cent; red cells, $4 \cdot 7 \mathrm{~m}$. per cu. $\mathrm{mm}$.; leucocyte count, 4300 per cu. $\mathrm{mm}$.; platelet count, 300,000 per cu. mm.; prothrombin time, 53 seconds (control 30 seconds). Van den Bergh, positive; delayed direct and indirect reactions; quantitative, $2 \cdot 4$ units. Plasma proteins: albumin 3.1 g, globulin $3.3 \mathrm{~g}$. Thymol turbidity, 3 units. Wassermann reaction, negative.

No bleeding occurred during the stay in hospital, and the patient was discharged in good general health on April 10, 1948.

Comments. This case had been regarded as an example of "Banti's syndrome." The splenomegaly followed by hepatomegaly, the thrombocytopenia, and the melæna of 1942, in the absence of a demonstrable radiological lesion in the œsophagus and gastrointestinal tract, support this view. However, the progressive anæmia usually associated with this syndrome was not present. The recent hæmorrhage and the hæmatemesis in 1944 may have originated from the osophageal varices first shown by a barium swallow in that year. The presence of the epigastric thrill and murmur 
were indicative of the hidden veins of a collateral circulation in the abdominal wall and, it will be shown later, supported a diagnosis of hepatic fibrosis.

Clinical Diagnosis. Cirrhosis of the liver with œsophageal varices and a collateral circulation in the falciform ligament and abdominal wall, producing a continuous hum and thrill.

\section{Previously Reported Cases}

Laennec (1819) gave the first description of the venous hum. It was heard in the neck, and was considered by him to arise in the carotid arteries. Pégot in 1833 described a soft murmur heard over subcutaneous abdominal varices in an alcoholic soldier. A necropsy revealed a large spleen, "small liver," and a " patent umbilical vein." An account of this case was also published by Cruveilhier (1835). A more detailed description of the venous hum occurring in cirrhosis was given by Trousseau in 1868. He was accompanied at the necropsy of such a case by Sappey who dissected the porto-systemic anastomoses which were found in the falciform ligament and abdominal wall.

Further accounts of the hum have appeared in clinical records from time to time. The majority of these are mentioned by Armstrong and his associates (1942) in their discussion on the CruveilhierBaumgarten syndrome. Other cases, not recorded by these authors, have been reported by Hall (1922, 1937), Lemierre and Garcin (1930), Gwyn (1930), Bates (1937), and Kenawy (1937, 1939).

\section{PORTO-SYSTEMIC ANASTOMOSES}

The venous hum in hepatic cirrhosis is dependent upon the formation of anastomoses between the portal and systemic circulations. Details of the many vascular communications that may develop in this condition are given by Rolleston and McNee (1929). In considering the features and mode of origin of the murmur, we are only concerned with those vessels that develop in the falciform ligament and abdominal wall. The former normally contains channels that establish communication between the left branch of the portal vein and the subcutaneous veins of the abdomen; these are the para-umbilical veins of Sappey and lie in close relation to the ligamentum teres.

In portal hypertension a large vein is often found in the free margin of the falciform ligament. Rokitansky and Bamberger stated that this was the patent umbilical vein, but Sappey, doubting the permeability of this structure, asserted that it was always a dilated para-umbilical vessel (Rolleston and McNee, 1929). Baumgarten found that in 55 of a series of 60 consecutive necropsies the umbilical vein remained patent for some 6-10 cm. from its connection with the left branch of the portal vein (Fontanel and Puig, 1931). More recently, Flynn (1946) reported a case of cirrhosis in which it was patent throughout its length. Rolleston and McNee (1929) have seen the vein full of growth in a case of cirrhosis with carcinoma.

In cases reported by Catti (1907), Florand (1922), Picchini (1890) and Armstrong et al. (1942), the vessel in the free margin of the falciform ligament was considered to be the umbilical vein, whereas in the cases of Lutembacher (1936), Lemierre and Garcin (1930) and others, it was clearly a dilated para-umbilical vein. In Case 1 described here, a large vein was present in part of the free margin of the falciform ligament, the remaining portion being occupied by the ligamentum teres; this vessel may, therefore, be considered as the patent section of the obliterated umbilical vein referred to by Baumgarten.

A large channel running anteriorly in the falciform ligament connecting the umbilical or paraumbilical veins with the superior epigastric or internal mammary veins has been seen at necropsy in cases of portal obstruction (Hall, 1937; .. Lemierre and Garcin, 1930). It appears to have been an example of the para-umbilical-xiphoid vein of Braune (von Braune, 1884) and was present in Case 1 reported here. 
Features, Origin, AND OCCURRence OF THE Hum

Venous Hums in General. The continuous humming bruit is most often heard in the neck, arising from the jugular veins of normal children and anæmic adults. It may be necessary to put these vessels on the stretch (by lifting and turning the head to the other side) before the hum can be heard. Laennec (1819) was the first to describe the murmur and likened it to the sound " of the sea or that which is produced by the application of a large shell to the ear." Hope (1849) compared it to the whispered word " who." Bouillaud (1835), quoted by Hope, called it the " bruit de diable," but the latter preferred the term "venous-hum." Occasionally, the murmur may have a musical quality, so much so that Laennec, describing the phenomenon in a case, said, "I at first conceived the sound to arise from an instrument in the apartment below." The cervical hum was considered both by Laennec and Bouillaud to arise in the carotid arteries. Ogier Ward (1837) and Hope (1849) pointed out the venous origin of the murmur.

Venous Hums in Hepatic Cirrhosis. The murmur in cirrhosis is usually localized to the region of the xiphoid process (Case 2) or the umbilicus, but considerable radiation may occur (Case 1). It has been detected over the præcordium (Gwyn, 1930), the lower end of the sternum (Catti, 1907; Hall, 1922), the sternum and hepatic area (Gambarati, 1903; and our Case 1) and the abdomen and back (Florand, 1922). Occasionally, more than one focus of sound may be present (Lutembacher, 1936; Armstrong et al., 1942).

Accentuation of the murmur may occur during systole, inspiration, and in the erect or sitting posture compared with the recumbent. Rarely, it may occur during cardiac diastole (Gambarati, 1903; Fontanel and Puig, 1931). The hum may become softer or disappear either spontaneously (Rolleston and McNee, 1929; Gambarati, 1903) or after paracentesis (Catti, 1907; Picchini, 1890; Lutembacher, 1936). It has disappeared with the onset of ascites a short time before death (Thayer, 1911; Lemierre and Garcin, 1930); this may have been the result of portal thrombosis.

A thrill may be present at the site of maximum intensity of the hum. It is usually slight, and detected by light finger-pressure. Obvious subcutaneous varicose veins are present in the majority of cases in the region of the hum and thrill. In some instances they may be revealed only after careful inspection or palpation, whilst in others, dissection at necropsy may be required to display them. Occasionally, dilated veins may be present in the thoracic wall. Application of firm pressure over or just below the site of the thrill and hum usually leads to their disappearance with subsequent reappearance on release of the compression.

Gambarati (1903), Bates (1937), and others, and Hale-White (1945), have considered the hum to arise in the inferior vena cava narrowed by peri-venous hepatic fibrosis. This view is not substantiated by necropsy findings, the vessel being invariably normal. Thayer (1911) emphasized the superficial origin of the phenomenon. He considered it to be produced by blood passing under pressure through the varying calibre of the abdominal varicosities. This is the view of Lemierre and Garcin (1930), Lutembacher (1936) and Hall (1937); it is supported by the clinical features and necropsy findings of cases previously reported, and by the circumstances of the cases here presented. When no obvious subcutaneous varicosities are present, the hum has been thought to arise in a tortuous umbilical or para-umbilical vessel in the falciform ligament, but it is probable that necropsy would reveal the presence of more superficial channels. The existence of the murmur over the pracordium is usually the result of transmission from the abdomen by way of subcutaneous varices in the chest wall or dilated internal mammary veins.

Anæmia is not essential for the production of the hum, but may play a part in the intensity and radiation (Lutembacher, 1936). In Case 1, reported here, no change with fluctuation in hæmoglobin percentage resulting from repeated hæmatemeses and transfusions was observed. The hum may be present at the time when the cirrhosis is diagnosed, but it may not appear until after an interval of months (Fontanel and Puig, 1931) or years (Taylor, 1895). It may sometimes be the presenting feature, evidence of cirrhosis appearing only later (Gywn, 1930).

The characteristics of the hum have been described in cases of portal, monolobular (Hall, 1937), bilharzial (Kenawy, 1937, 1939) and syphilitic cirrhosis. Armstrong and his associates (1942), 
collecting previously reported cases of venous hum, found 42 examples. Although necropsies were performed in only half this number, most appeared to be associated with hepatic fibrosis. Venous hums may occur in other forms of portal obstruction, such as hypoplasia of the right branch of the portal vein.

The para-xiphoid-umbilical hum indicates the presence of portal obstruction beyond the origin of the para-umbilical veins and umbilical vein (ligamentum teres). It has, apparently, only been reported in conditions associated with hepatic fibrosis. The incidence of the phenomenon is not high, but perhaps it is often overlooked. But even when all the necessary factors for the production of a hum appear to be present (i.e. portal hypertension and porto-systemic anastomoses with abdominal varicosities), no sound may be heard. Furthermore, it is quite common to meet with extreme hepatic cirrhosis in the absence of dilated channels in the falciform ligament and abdominal wall.

Originally, Cruveilhier (1835) considered the fundamental lesion to be a congenital patency of the umbilical vein with the resulting shunt of blood away from the liver leading to subsequent atrophy. Von Baumgarten (1908) suggested that the shunt was secondary to congenital hypoplasia of the liver and portal system. In 1922 Hanganutz introduced the term "Cruveilhier-Baumgarten cirrhosis" and this has been frequently used by French authors.

Armstrong and his colleagues suggest that the term "Cruveilhier-Baumgarten syndrome" be applied to patients showing a clinical picture of portal hypertension characterized by a loud abdominal murmur and thrill. If necropsy reveals the presence of a patent umbilical vein and hepatic atrophy with little or no fibrosis, the case is considered to be an example of " CruveilhierBaumgarten disease" (i.e. primary porto-systemic shunt due to persistent patency of the umbilical vein with subsequent hepatic atrophy). The authors refer to 4 reported cases of this "disease" and add one of their own. The claim, however, that the liver changes in these cases are not those of ordinary coarse cirrhosis is not convincing.

\section{DifFerential Diagnosis}

A continuous abdominal hum may be heard in conditions other than those associated with hepatic fibrosis. Such a murmur may arise from the inferior vena cava, and should be recognized without difficulty. It is occasionally heard in the normal subject, but more often in the presence of anæmia. It is best heard just above and to the right of the umbilicus, radiating along the line of the vessel. A similar bruit may be present over an enlarged spleen (Roeser, 1862), and Catti estimated that it is heard over this organ in every fifth or sixth case of cirrhosis (Rolleston and McNee, 1929).

A continuous hum has been found over a liver that was the seat of malignant disease (Lauder Brunton, 1896). It may be due to a very vascular tumour or possibly to compression of the portal vein by growth or enlarged glands (Rolleston and McNee, 1929). Very rarely, an arterio-venous fistula may develop in the abdomen, usually the result of rupture of an aortic aneurysm into the inferior vena cava. The resulting continuous murmur is accompanied by the general vascular signs of arterio-venous communication. The "souffle" occasionally heard over the lower abdomen in pregnancy or in the presence of fibroids will not give rise to confusion, but is mentioned for the sake of completeness.

A number of cases of cirrhosis have been reported in which transmission of the hum occurred upwards over the sternal region. Occasionally, the thoracic distribution is the salient feature. It is particularly in these cases that confusion may arise, the most frequent error being a diagnosis of congenital heart disease. In view of this, Gwyn (1930) advises a search for evidence of cirrhosis, including the presence of subcutaneous varicosites about the epigastrium and sternal regions, when a congenital heart lesion is suspected.

Three conditions may give rise to a murmur in the chest resembling that heard in cirrhosis, namely, persistent ductus arteriosus, arterio-venous fistula, and murmurs arising in the great veins. Diagnosis in the former two should not be difficult. Regarding the third, it is important to recognize the venous hum frequently met with (and already described) in healthy school children. The chief 
importance of this hum is that it may give rise to a mis-diagnosis of congenital heart disease (Sawyer, 1910; Coombs, 1911; Landis and Kaufman, 1912; Palmer and White, 1928).

Auscultation of the abdomen is advised in patients with splenomegaly or features suggesting chronic liver disease, for the para-xiphoid-umbilical hum is almost pathognomonic of hepatic cirrhosis. The presence of this murmur makes laboratory tests for liver function, including liver biopsy with its attendant dangers, largely unnecessary for establishing the diagnosis. Furthermore, the sign points to the presence of hepatic fibrosis even if all these special investigations are negative. In a number of cases the bruit is present in the absence of obvious varicosities, and it is particularly in these that auscultation is of value.

\section{SUMMARY}

Two cases of cirrhosis of the liver are reported in which a collateral circulation in the falciform ligament and abdominal wall produced a continuous venous hum and thrill.

Reference is made to the porto-systemic anastomoses which may develop in the falciform ligament and abdominal wall in cirrhosis.

The features of the murmur are described, its occurrence and significance considered, and the mode of production discussed. - Reference is made to the "Cruveilhier-Baumgarten syndrome."

A brief survey is made of other continuous bruits heard over the abdomen and thorax.

Attention is drawn to the value of abdominal auscultation in patients with splenomegaly or suspected chronic liver disease.

I am indebted to Dr. G. E. Beaumont, who discovered the murmur in Case 1, for encouragement and permission to publish this case; to Dr. G. E. S. Ward for permission to publish Case 2; to Professor R. W. Scarff for the postmortem report; to Dr. E. A. Fairburn for helpful criticism; and to Mr. M. E. Sandervorst for assistance with the foreign translations.

\section{REFERENCES}

Armstrong, E. L., Adams, W. L., Tragerman, L. G. and Townsend, E. W. (1942). Ann. intern. Med., 16, 113.

Bates, J. L. (1937). Lancet, 1, 1108.

Brunton, T. Lauder (1896). Trans. med. Soc. Lond., 19, 117.

Catti, G. (1907). Z. klin. Med., 61, 269.

Coombs, C. (1911). Brit. J. Child. Dis., 8, 109.

Cruveilhier, J. (1835). Anatomie Pathologique du Corps Humain, Paris.

Florand, M. A. (1922). Bull. Soc. méd. Hôp. Paris, 46, 1342.

Flynn, J. E. (1946). J. Iowa Med. Soc., 36, 52.

Fontanel, P. and Puig, R. (1931). J. Med. Lyon, 12, 89.

Gambarati, V. (1903). Quoted by Thayer.

Gwyn, N. B. (1930). Amer. J.-med. Sci., 180, 525.

Hale-White, W. (1945). Index of Differential Diagnosis, Bristol.

Hall, A. J. (1922). Brit. med. J., 1, 592.

- (1937). Lancet, 1, 1202.

Hanganutz, P. (1922). Pr. méd., 30, ii, 732.

Hope, J. (1849). A Treatise on the Disease of the Heart and Great Vessels, etc., London.

Kenawy, M. R. (1937). Lancet, 1, 1281.

(1939). Ibid., 1,821.

Laennec, R. T. H. (1819). A Treatise on the Diseases of the Chest and on Mediate Auscultation, London.

Landis, H. R. M. and Kaufman, I. (1912). Arch. Pediat., 29, 88.

Lemierre, A. and Garcin, R. (1930). Rev. Médecine, 47, 387.

Lutembacher, R, (1936). Pr. méd., 44, 847.

Palmer, R. S. and White, P. (1928). New Engl. J. Med., 199, 1297.

Pégot (1833). Bull. Soc. anat. Paris, 8, 49.

Roeser (1862): Bull Acad. Imperiale med., 28, 18.

Rolleston, H. and McNee, J. W. (1929). Diseases of the Liver, Gall-bladder and Bile-ducts, London.

Sawyer, J. E. H. (1910). Brit. J. Child. Dis., 7, 310.

Taylor, F. (1895). Guy's Hosp. Rep., 52, 50 .

Thayer, W. S. (1911). Amer. J. med. Sci., 141, 313.

Trousseau, A. (1868). Clin. med. Hotel-Dieu, 3, 526, 527.

von Baumgarten, P. (1908). Arb. path. Anat. Bakt., 6, 93.

von Braune, W. (1884). Das Venensystem des Menechlichen Konpers, Leipzig.

Ward, O. T. (1837). London Medical Gazette, $20,7$. 